\title{
Letter to the editor: The measles outbreak in Bulgaria, 2009-2011: an epidemiological assessment and lessons learnt - but not completely yet
}

D Poddighe ${ }^{1}$

1. ASST Melegnano e Martesana, Vizzolo Predabissi (Milano, Italy) and Università degli Studi di Pavia.

Correspondence: Dimitri Poddighe (dimimedpv@yahoo.it)

Citation style for this article:

Poddighe D. Letter to the editor: The measles outbreak in Bulgaria, 2009-2011: an epidemiological assessment and lessons learnt - but not completely yet. Euro Surveill. 2016;21(13):pii=30178. DOI: http://dx.doi.org/10.2807/1560-7917.ES.2016.21.13.30178

Article submitted on 22 March 2016 / accepted on 31 March 2016 / published on 31 March 2016

To the editor: The recent report by Muscat et al., on the 2009 to 2011 measles outbreak in Bulgaria, emphasised that this infectious disease still represents a health issue of concern that can re-emerge with a substantial magnitude in Europe [1]. Indeed, this epidemiological analysis recorded 24,364 cases in Bulgaria between April 2009 and December 2011 and, importantly, around $73 \%$ of those infected were children and adolescents $<15$ years of age. According to a previous national survey, almost $30 \%$ of children aged 2 to 10 had not been immunised against measles [2]. Moreover, most cases occurred in the Roma ethnic group, where the immunisation rate was even lower than in the rest of the Bulgarian population [1].

The experience described illustrates that measles can still spread in European countries, if the vaccination coverage is not appropriate and, especially, if there are predisposing conditions, such as vulnerable ethnic groups, immigrants from endemic countries, as well as socially and economically disadvantaged people

In addition, the very recent report of a measles outbreak in a refugee settlement in Calais, France, between January and February 2016, reinforced the concept that the current measles threat does not necessarily result from individuals originating from outside Europe only, as the measles genotype identified in this outbreak is known to be one of the main measles strains circulating in Europe. Thus, the initial contamination might have come from a non-immunised European volunteer [3] and the refugee settlement with vulnerable individuals acted as an 'epidemiological amplifier' of this communicable infection. However, that was a small outbreak with limited number of cases.

The important lesson that Europe still needs to learn, or be reminded of, is that measles has not been eradicated yet and, that therefore, European countries cannot let down their guard, especially considering the current considerable migration of people from areas where the disease is endemic and where the vaccination programmes have been impacted by armed conflicts.

An important aspect of the Bulgarian outbreak is highlighted in the analysis of measles-related deaths and its age distribution. The authors recorded 24 fatal cases with 19 of them occurring in children «15 years. Importantly, 11 measles-related deaths were in the paediatric population aged $<1$ year and another 5 cases were in the 1 to 4 years age group.

Indeed, in most developed countries, the measles, mumps, rubella (MMR) vaccine schedule consists of two doses: the first dose is usually administered between 12 and 15 months of life; the second dose is proposed at 5 to 6 years or 11 to 12 years of age, according to the respective national or regional plan. As a consequence, neonates and young infants are not actively immunised and their source of protection relies upon measles herd immunity and/or maternal antibody transmission, which anyway does not persist beyond the first 6 to 9 months of life [4]. Therefore, young infants represent the most susceptible population target of the infection and they are also the most vulnerable individuals to develop severe complications, as it is indicated by their case-fatality ratio during the Bulgarian outbreak (0.28\%, compared with the overall rate of $0.1 \%$ ) [1]. Moreover, measles infection early in life can predispose to later neurological complications, such as subacute sclerosing panencephalitis (SSPE); indeed, in infants \& 1 year, the prevalence is around 1 SSPE case per 5,000 infections vs 1 SSPE case per 25,000 in those infected overall $[5,6]$.

According to current knowledge, herd immunity can be achieved through an immunisation rate $>95 \%$ in the general population. Unfortunately, in the study by Andrews et al., evaluating measles susceptibility in 
17 European countries, only seven met World Health Organization targets of immunisation against measles [2]. Recently, on 27 January 2016, the Italian Public Health Institute (Istituto Superiore di Sanita', ISS) published the assessment of the protection against measles in Italy which resulted in a national vaccination coverage of $82-83 \%$ with a great variability among Italian regions, ranging from $65 \%$ to $92 \%$. Moreover, the vaccine coverage of the whole population was shown to decrease gradually over the years [7].

In conclusion, the mortality analysis during the measles outbreak can help us convey an important message to parents: establishing and maintaining an immunisation rate able to promote herd immunity is the only way to protect our offspring against measles in the first years of life, when their active immunisation process has not been completed yet. Communicating results from mortality analysis could reinforce vaccination campaigns for measles, by helping parents to recognise the importance of MMR vaccine, as nowadays a number of them refuse and/or underrate this means of protection.

\section{Conflict of interest}

None declared.

Authors' contributions

Dimitri Poddighe conceived and wrote the manuscript.

\section{References}

1. Muscat M, Marinova L, Mankertz A, Gatcheva N, Mihneva Z, Santibanez S, et al. The measles outbreak in Bulgaria, 20092011: An epidemiological assessment and lessons learnt. Euro Surveill. 2016;21(9):30152. DOI: 10.2807/1560-7917. ES.2016.21.9.30152 PMID: 26967661

2. Andrews N, Tischer A, Siedler A, Pebody RG, Barbara C Cotter S, et al. Towards elimination: measles susceptibility in Australia and 17 European countries. Bull World Health Organ. 2008;86(3):197-204. DOI: 10.2471/BLT.07.041129 PMID: 18368206

3. Jones G, Haeghebaert S, Merlin B, Antona D, Simon N, Elmouden $\mathrm{M}$, et al. Measles outbreak in a refugee settlement in Calais, France: January to February 2016. Euro Surveill. 2016;21(11):30167. DOI: 10.2807/1560-7917.ES.2016.21.11.30167 PMID: 27020578

4. Abad CL, Safdar N. The reemergence of measles.Curr Infect Dis Rep. 2015;17(12):51. DOI: 10.1007/S11908-015-0506-5 PMID: 26446612

5. Liu L, Oza S, Hogan D, Perin J, Rudan I, Lawn JE, et al. Global, regional, and national causes of child mortality in 2000-13, with projections to inform post-2015 priorities: an updated systematic analysis. Lancet. 2015;385(9966):430-40. DOI: 10.1016/S0140-6736(14)61698-6 PMID: 25280870

6. Fisher DL, Defres S, Solomon T. Measles-induced encephalitis. QJM. 2015;108(3):177-82. DOI: 10.1093/qjmed/hcu113 PMID: 24865261

7. Ministero della Salute. 27 Gennaio 2016. Morbillo-parotiterosolia (MPR), trend in diminuzione della copertura vaccinale. [Measles-mumps-rubella (MMR), diminishing trend following vaccine coverage]. Italian. Available from: http://www.salute. gov.it/portale/news/p3_2_1_1_1.jsp? lingua=italiano\&menu=n otizie $\& p=$ dalministero\&id $=2420$.
License and copyright

This is an open-access article distributed under the terms of the Creative Commons Attribution (CC BY 4.0) Licence. You may share and adapt the material, but must give appropriate credit to the source, provide a link to the licence, and indicate if changes were made.

This article is copyright of the authors, 2016. 